\title{
Interior Design of Workplace and Performance Relationship: Private sector corporations in Egypt
}

\author{
Rasha Mahmoud Ali El-Zeiny \\ Faculty of Fine Arts, \\ Minia University, Minia, Egypt \\ rashaelzeney@yahoo.com
}

\begin{abstract}
In today's competitive business environment, corporations can no longer afford to waste the potential of their workforce. There are important factors in the employee's workplace that influence significantly on their level of motivation and performance. The main objective of the study is to understand the relationship between the employees' performance and their physical work environment. The private sector corporations of Egypt have been chosen as the population for the study. The results of the study show that office design has a substantial impact on the employees' performance.
\end{abstract}

Keywords: Interior Design; Workplace; Performance; Egypt.

eISSN 2514-751X @ 2018. The Authors. Published for AMER ABRA CE-Bs by e-International Publishing House, Ltd., UK. This is an open access article under the CC BY-NC-ND license (http://creativecommons.org/licenses/bync-nd/4.0/). Peer-review under responsibility of AMER (Association of Malaysian Environment-Behaviour Researchers), ABRA (Association of Behavioural Researchers on Asians) and cE-Bs (Centre for EnvironmentBehaviour Studies), Faculty of Architecture, Planning \& Surveying, Universiti Teknologi MARA, Malaysia.

DOI: https://doi.org/10.21834/aje-bs.v3i7.263 


\subsection{Introduction}

In today's competitive business environment, corporations can no longer afford to waste the potential of their workforce. There are important factors in the employee's workplace that influence significantly on their level of motivation and performance. The literature reveals that good office design has a positive effect on employees' productivity; this hypothesis is being tested in this study. In the context of Egypt, this is a relatively new topic, and there are not any studies in the field of interior design, so the purpose of this paper is to analyze the influence of the workplace interior design factors on employees' performance in the private sector corporations in Egypt. The study is limited to the interior design of the facility and does not address other aspects of the work environment.

\subsection{Literature Review}

\section{Defining Job Performance}

Campbell, J. P. (1990) defines performance as behavior, It is something done by the employee. This concept differentiates performance from outcomes. Outcomes are the result of a person's performance, but also, there are many factors that assess outcomes than just an employee's behaviors and actions. When Campbell (1990) defining performance as behavior, he allows for exceptions. For instance, he states that performance does not have to be directly observable actions of a person. It can consist of mental productions such as answers or decisions.

The measures of this study are based on personnel's subjective assessments. Wang and Gianakis (1999) have defined subjective performance measure as an indicator used to determine individuals' aggregated perceptions, attitudes or assessments toward a corporation product or service. Subjective performance data are usually collected using survey questionnaires. Subjective data can also be descriptive or qualitative collected by interviews (Amina Hameed, ShehlaAmjad, 2009).

\section{Workplace Interior Design}

Interior design defined by the National Council for Interior Design Qualification(NCIDQ), as the art and science of understanding people's behavior to create functional spaces within a building through creative and technical solutions. Within a structure, these solutions are applied to achieve a built interior environment, and they are functional, enhance the quality of life and culture of the occupants and are aesthetically appealing. Workplace Interior design is a key factor in job satisfaction. It affects the way in which employee's work. Workplace design may enhance organizational success by creating workplace that support work quality, quantity and style, while improving turnover and absentee rates (Becker, 1981).

Increasingly, architects, interior designers and facilities managers are assuming the new role strategic consultants familiar with human behavior and organization (Hamilton, Baker \&Vlasic, 1997). A growing number of companies are using the interior design of workplace as a tool to help attract and keep employees; the latest American Society of Interior Designers (ASID, 1999) research shows that the physical environment is one of the top three factors 
that affect their decisions to accept or leave jobs, and it was tied for second with benefits after compensation.

\section{Workplace Design and Employees' Performance}

Over the years, many corporations have been trying new designs and techniques in office buildings, which can promote productivity, and attract more employees (Amina Hameed, ShehlaAmjad, 2009). Many authors have noted that, the workplace design, along with effective management processes, is playing an important role in increasing employees' productivity and boosting organizational performance (Uzee, 1999; Leaman and Bordass, 1993; Williams et al. 1985).

Research by the architects, Gensler (2005) of 200 UK business managers showed that an improved workplace would boost employee productivity by 19 per cent and their own productivity by 17 per cent. These improvements have great implications for the economy if proven. Gensler (2006) followed up this research in a survey of 2,000 office employees in the USA which showed that 90 per cent of the respondents believed that better interior design and layout result in better general employee performance.

\section{Interior Design Factors that Impact on Productivity and Performance}

Brill et al. (1984) ranked factors, which impact on productivity according to their significance. The factors are sequenced based on the importance: Furniture, Noise, Flexibility, Comfort, Communication, Lighting, Temperature and the Air Quality. Springer Inc (1986) stated that an insurance company in a study showed that the ergonomic furniture increased performance by 10 to 15 percent. Today's workforce believes a noisy work environment inhibits effective work. Statistics from the Data Management Association show that a lack of acoustical privacy in open-plan offices can reduce productivity by as much as 40 percent and increase errors by as much as 27 percent (McLaughlin, 2000). In recent studies, Lighting was found to be the main factor, which impact on the daily and general productivity of employees in workplaces. The Commission for Architecture \& the Built Environment and the British Council for Offices carried out a study revealed that even simple things such as adequate lighting and having proper daylight can decrease absentee rate by 15 per cent. Also, they increase productivity by between 28 per cent and 20 per cent.

There is an important effect of temperature and humidity on how tired someone might feel, currently there are no regulations governing high temperature levels in the workplace and the responsibility of companies to their employees in this respect, although the World Health Organization recommends a maximum working temperature of $24^{\circ} \mathrm{C}$ (Kathy F. Montgomery, 2004).In a study, (ASID, 2002) employees were asked what they want in their ideal workplace. Thirty percent of the employees mentioned access as pivotal in the office environment. They relate access to the proximity of things they need, including access to spaces that accommodate the tasks they need to accomplish, access to office equipment and to people. In the same study, employees identified privacy as important to their ability to work productively.

The opportunity to view natural settings through a window, to human productivity and well-being is the subject of significant research, Roger Ulrich's (2002), Texas A \& M 
University research team explored the links between flowers and plants and workplace productivity. When plants and flowers were added to the work environment, subjects in the study, both men and women demonstrated more innovative thinking and created innovative solutions to office problems (Uhich, 2003). Colors also can have an important effect on the space users.

\subsection{Methodology}

The research work is a descriptive research of both primary data and secondary data. The paper presents the analysis of the workplace interior design at different private sector corporations in Egypt; the research paper would seek to fulfil the following listed objectives:

1. To analyze the factors of workplace interior design affecting the employee's performance.

2. To assess whether workplace design is one of the factors in affecting employees' performance.

3. To analyze the influence of office design if any on gender or age of employees.

The study has been carried out with 6private sector corporations with different work areas as a sample. These corporations are Dar Al-Handasah Consultants, Egypt Kuwait Holding, Gas Chil, Samcrate Contractors, ECG Engineering Consultants Group, KPMG Hazem Hassan Public Accountants. A total of 129 employees from these 6 corporations were taken as the sample size.

A questionnaire was used to collect primary data and observation was used to collect information about the interior design. The study used a five point Likert Scale to measure all the variables, but the questions in the questionnaire for the subjective performance measurement were in percentages. The statistical techniques were used to analyze the response.

\subsection{Results and Discussions}

The research focused on nine indicators of workplace interior design which considered for study in the survey, and took note into account that these design elements should not be considered the only factors that may have an impact on the performance of the employees in an interior environment. These indicators are furniture, noise, temperature, lighting, spatial arrangement, color, outside view and presence of plants and flowers, (See figure 1).

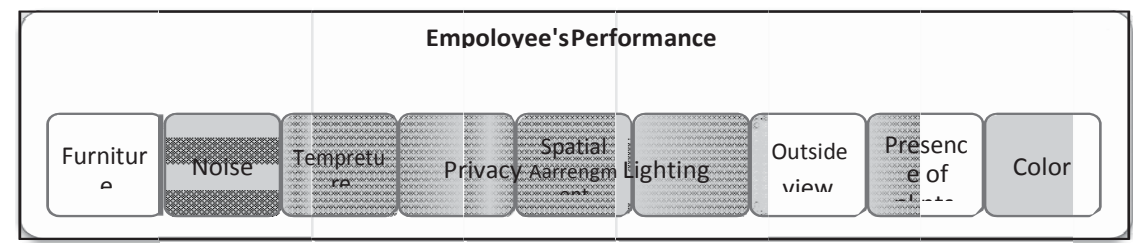

Figure 1: Interior Design Factors Considered for Study in the Survey 


\section{Influence of Workplace Design on Employees' Performance}

The data reveal that the vast majority of employees (96\%) believe that superior office design leads to superior overall performance, also makes a company more competitive. According to the results in figure $2 \mathrm{a}, 44 \%$ of the respondents believe that their overall productivity will increase more than $50 \%$ if the related office design problems are solved, and about $52 \%$ of the respondents believe that their performance will be increased from $30 \%$ to $10 \%$.However, employees who believe that the workplace design has no effect on their performance were $4 \%$. which indicates that good workplace design can make a substantial difference in staff performance, and consequently has a positive impact on the corporations' productivity.

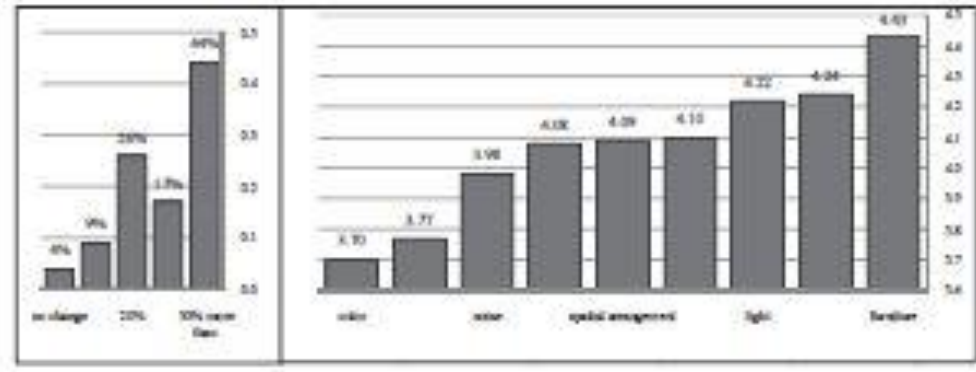

(a) (b)

Figure 2: (a) Influence of Workplace Design on Performance;

(b) Mean Ratings of Factors Affecting Performance

In Figure $2 b$, data was analyzed to identify the factor that has a high effect on decreasing employee's performance. The average mean ranking indicates that the variable 'furniture' is the most contributing factor, which affect the performance of employees. This means that Ergonomics of office furniture has great importance because an employee has to work with them all the time that he is on office, and if they are neither comfortable nor user friendly, their working style and efficiency will get hamper considerably. Next to furniture, it is temperature, as it can have a significant effect on the performance of an employee. In hot environments, it is common for employees to become irritable and less efficient. However, light came in the third rank.

Contrary to expectations, the presence of plants and flowers has been given fourth rank, followed by spatial arrangement. While privacy and noise have gotten less ranking, which indicates that there is a link between flowers and plants, as well as other aspects of nature, and employees' performance. Outside view and color have been given the lowest significance.

\section{Satisfaction Ratings of Different Aspects of the Workplace Environment}




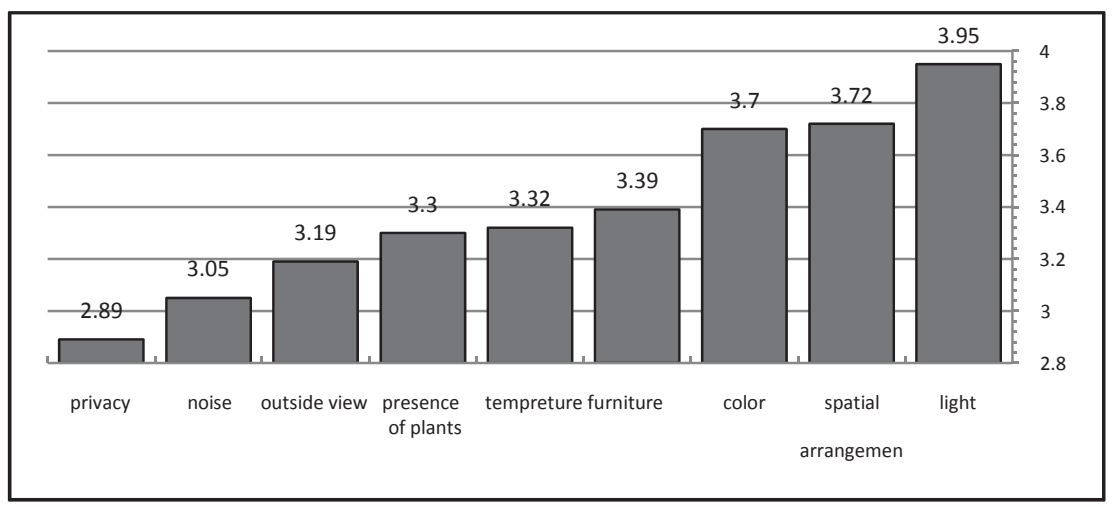

Figure 3: Mean Rating of Satisfaction with Aspects of the Physical Workplace

Employees were asked to rate their satisfaction with aspects of their physical workplace. According to the results in figure 3, the most dissatisfying is the privacy; this is key, given the fact that privacy has a vital influence on job satisfaction. The respondents clarified privacy to mean a space away from distractions. This response would indicate that the corporations may need for different types of work spaces, perhaps available by task, whether a space for "heads down" concentration or a more social team project spaces. Furthermore, the noise, the outside view, temperature, presence of plants, and furniture also contributes to the dissatisfaction feedback. However, the three highest satisfaction ranking are lighting followed by access to people and equipments and color. This is indicating that the 6 corporations have proper and adequate light, and highly cared about access to the proximity of things employees need.

\section{Overall Responses According to Gender}

The data collected showed that 29 percent respondents were female, and 71 percent were male.

The overall mean of all the factors in figure 4 indicates that female employees are more affected by the physical workplace than the male employees, and they are less satisfied with the interior work place environment.

The overall response according to the gender is detailed in a table for each gender. There are some differences amongst the responses to different factors in the workplace. The average mean ranking in tables 1 and 2 , indicated that for male and female, furniture was the most influential factor. Male respondents' results showed that temperature has been given the second rate followed by space; however, color has been given the lowest significance. In the same way, an analysis of female employees' results showed that light is ranked second followed by temperature, while outside view has been given the last rank. The comparison of male and female ratings also showed that female was more affected by privacy than male. This may be due to the social traditions in Egypt, since privacy is an important 
issue.

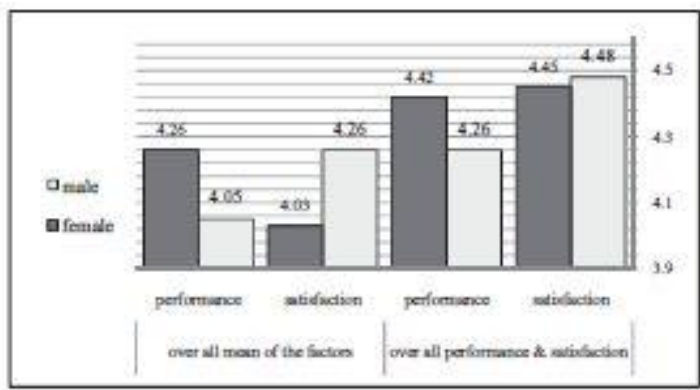

Figure 4: Overall mean According to Gender

Table 1: Male Response

\begin{tabular}{|c|c|c|c|c|c|c|c|c|c|}
\hline Factor & Furniture & Temperature & $\begin{array}{c}\text { Spatial } \\
\text { Arrangement }\end{array}$ & $\begin{array}{l}\text { light } \\
\text { Presence of } \\
\text { Plants }\end{array}$ & privacy & Noise & $\begin{array}{l}\text { utside } \\
\text { View }\end{array}$ & Color \\
\hline Rank & 1 & 2 & 3 & 4 & 5 & 6 & 7 & 8 & 9 \\
\hline Mean & 4.48 & 4.31 & 4.26 & 4.17 & 4.05 & 4.01 & 3.98 & 3.76 & 3.61 \\
\hline
\end{tabular}

Table 2: Female Response

\begin{tabular}{|c|c|c|c|c|c|c|c|c|c|}
\hline Factor & Furniture & Light & Temperature & Privacy & $\begin{array}{l}\text { Presence of } \\
\text { Plants }\end{array}$ & Noise & \begin{tabular}{|c|} 
Spatial \\
Arrangement
\end{tabular} & \multicolumn{2}{|c|}{$\begin{array}{c}\text { Color lutside } \\
\text { View }\end{array}$} \\
\hline Rank & 1 & 2 & 3 & 4 & 5 & 6 & 7 & 8 & 9 \\
\hline Mean & 4.45 & 4.44 & 4.41 & 4.29 & 4.26 & 4.12 & 4.03 & 3.96 & 3.72 \\
\hline
\end{tabular}

\section{Overall Responses According to Age}

According to the data, 55 percent respondents were generation Yers(under30), 35 percent were generation Xers employees (ages 30-460) and10 percent respondents were baby boomers (ages 47-66).

The respondents were asked if they can complete their daily tasks easily due to the overall office environment. The results in figure 5 showed that baby boomers had the highest mean, followed by Xers, then Yers. That is due to the corporations, which usually provide more care for the top positions in terms of furniture, space, privacy, and the other aspects of physical workplace and facilities, and most of the baby boom respondents occupy the top positions, follow them Xers.

The results in figure 5 also showed that the baby boom and Yers employees are more concerned about their workplace surroundings than Xers. 


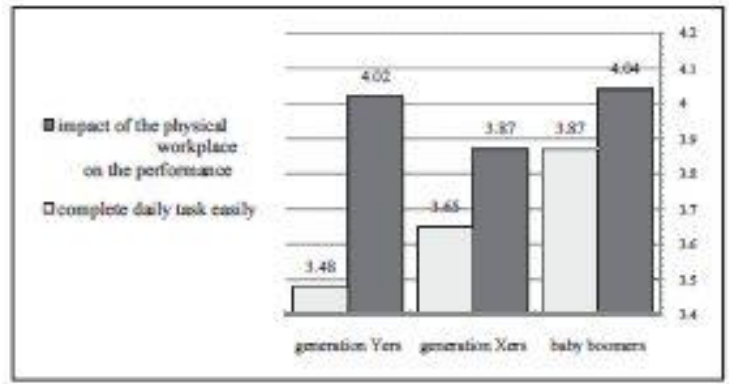

Figure 5: Overall mean According to Gender

Table 3: Differences between the Generations

\begin{tabular}{|l|c|c|c|c|c|c|c|c|c|}
\hline Factor & Furniture & $\begin{array}{c}\text { Temperatur } \\
\text { e }\end{array}$ & $\begin{array}{c}\text { Srangatial } \\
\text { Yrrant }\end{array}$ & $\begin{array}{c}\text { Presence } \\
\text { of Plants }\end{array}$ & Privacy & Noise & Light & $\begin{array}{l}\text { lside } \\
\text { View }\end{array}$ & Color \\
\hline Yers & 4.42 & 4.36 & 4.16 & 4.34 & 4.06 & 4.03 & 4.36 & 4.01 & 3.85 \\
\hline Xers & 4.53 & 4.27 & 4.25 & 3.96 & 4.16 & 4.01 & 4.12 & 3.63 & 3.67 \\
\hline $\begin{array}{c}\text { Baby } \\
\text { boomers }\end{array}$ & 4.24 & 4.45 & 3.93 & 3.52 & 4.05 & 4.24 & 4.25 & 3.02 & 3.52 \\
\hline
\end{tabular}

In table 3, results revealed that there are differences between the three generations. Temperature, light, noise and furniture stand out as the most important factors that affect the performance of the baby boom employees. For Xers, furniture is the leading factor to affect the performance, temperature is regarded second, followed by spatial arrangements. These results agree to a large extent with the Yers' results; since furniture has the highest mean, followed by temperature and light, then the presence of flowers and plants which considered, a high mean as compared with Xers and baby boomers. Most respondents of Yers believe that spaces, which contain plants and flowers, is supporting them to focus on the task which requires concentration, while some of Yers believe that the light music has an effect on their performance. The data also reveals that outside view ranked as the least factor in both baby boomers and Xers; however, it had a high mean in Yers, comparing with its means in the Xers and baby boomers.

\subsection{Conclusion}

Analysis of the collected data revealed that the interior design of the workplace had a substantial influence on the employees' performance. The overall impact of different elements showed that furniture affects the productivity of most employees; therefore, it is recommended that we have to consider ergonomic furniture while buying office furniture. The data also revealed that the majority of respondents lent weight to the presence of plants and flowers. The overall mean of all the factors showed that female employees are more concerned about their workplace interior design. Also male respondents' results showed 
that they were more affected by the temperature; however, female more affected by privacy. The response, according to age showed differences, the baby boom employees are more satisfied with their workplace environment; however, generation Yers are more concerned with the presence of plants and outside view than the other generations.

In conclusion, the majority of respondents believe that good workplace interior design can make a difference in their performance, and consequently have a positive impact on the corporations' productivity. So design professionals must expand their knowledge beyond real estate issues (efficiency) to understand what makes people perform and happy at work (effectiveness and desirability).

\section{Acknowledgment}

I would like to thank the human resource executive and employees of the corporations who participated in the survey.

\section{References}

American Society of Interior Designers (1999), Recruiting and Retaining Qualißed Employees by Design. White Paper.

AminaHameed, ShehlaAmjad (2009). Impact of Ofßce Design on Employees 'Productivity: a Case Study of Banking Organizations of Abbottabad, Pakistan(n.d.). Retrieved from http://www.scientificjournals.org/ journals2009/articles/1460.pdf

Brill, M., Margulis, S., Konar E., BOSTI. (1984). Using Ofßce Design to Increase Productivity. Vol. 1, 1984: Vol. 2, 1984. Buffalo, N.Y.: Workplace Design and Productivity Buildings/IAQ, pp.495 500.

Gensler Design + Performance Index, the U.S. Workplace Survey. (2006). www.gensler.com

Kathy F. Montgomery. (2004). Understanding the Relationship between the Design of the Workplace Environment and Wellness. Texas Tech University.

McLaughIm, C. (2000). Sound Solutions. ASID ICON June.

Milton, D.K., Glencross, P.M., Wafrers, M.D. (2000). Risk of Sick Leaves Associated with Outdoor Afr Supply Rate, Humidification, and Occupant Complaints. Informedesign www.informedesign.umn.edu. Accessed 01-07-04.

Steelcase, Inc. (2002). Workplace Acoustics: Sound, Noise and Effective Work, www.navbus.com. Accessed 729-04.

Ulrich, R. Ph.D., (2003). The Impact of Flowers and Plants on Workplace Productivity. Texas A \& M University.

US Army Corps of Engineers, (USAGE). (1997). Design Guide for Interiors.

Light and Color, Chapter 3, pg. 3.1-3.2.

Uzee, J. (1999). The Inclusive Approach: Creating a Place where People want to Work. Facility Management Journalofthe InternationalFacility Management Association, 26-30. 
Mahmoud Ali El-Zeiny, R. / Asian Journal of Environment-Behaviour Studies (ajE-Bs), 3(7) Mar / Apr 2018 (p.109-118)

Wargocki, P., Wyon, D.P., Sundell, J., Clausen, G. and Fanger, P.O. (2000). The Effects of Outdoor afr Supply Rate in an Ofßce on Perceived are Quality, Sick Building Syndrome(SBS) Symptoms and Productivity. Informedesignwww.informedesign.umn.edu.Accessed 12-08-03. 